\title{
Word imagery but not age of acquisition affects episodic memory
}

\author{
VERONIKA COLTHEART \\ City of London Polytechnic, London, England \\ and \\ EUGENE WINOGRAD \\ Emory University, Atlanta, Georgia
}

\begin{abstract}
Evidence is presented from two experiments and from a reanalysis of data published by Christian, Bickley, Tarka, and Clayton (1978) that the chronological age at which a word is acquired does not affect free recall or recognition memory. Morris's (1981) report, that late acquired words are better recalled than early acquired words, was not replicated and appears to be attributable to a difference in the emotionality value of his lists. Although the data are consistent with an interpretation in terms of semantic, but not episodic, memory tasks' beirg sensitive to word age of acquisition, it is suggested that a more fine-grained analysis is necessary.
\end{abstract}

It has been known for a long time that concrete, highimagery words are easier to remember than abstract, lowimagery words. An early demonstration of this phenomenon was reported by Stoke (1929), who studied free recall in children aged 10 and 11 as well as in college students. Later, more systematic studies which controlled word frequency also found that concrete words are easier to remember in recognition memory tasks (Gorman, 1961), paired associates learning (Epstein, Rock, \& Zuckerman, 1960; Paivio, 1963; Yarmey \& Paivio, 1965), and free recall learning (Tulving, McNulty, \& Ozier, 1965). Paivio, Yuille, and Rogers (1969) further demonstrated that word imagery has powerful effects on free recall and serial learning when word meaningfulness and word frequency are controlled.

More recently, a psychologically interesting property of words-the chronological age at which words are acquired-has been shown to affect retrieval from semantic memory. Word age of acquisition is measured by having subjects estimate the age at which they learned various words. There are two sources of evidence for the validity of this procedure. One source is to be found in two validity studies reported by Gilhooly and Gilhooly (1980). They found that adults' age-of-acquisition ratings correlated .94 with the age at which children could offer a minimally satisfactory definition. In a second study, Gilhooly and Gilhooly (1980) found a correlation of .93 between adults' ratings of word age of acquisition with the rank ordering, according to age norms, of words on a standard vocabulary test.

Requests for reprints should be sent to V. Coltheart, Psychology Department, City of London Polytechnic, Old Castle Street, London E1 7NT, England.
The second source of support for the importance of word age of acquisition (AOA) is to be found in the experimental literature showing the aforementioned strong effects of AOA on retrieval from the internal lexicon. Carroll and White (1973) found that rated age of acquisition of words correlated well with objective measures of AOA and that this variable determined picture-naming latency. Subsequent studies have confirmed this finding (Lachman, 1973; Lachman, Schaffer, \& Hennrikus, 1974). Loftus and Suppes (1972) found that AOA also determined categoryinstance naming. Gilhooly and Gilhooly (1979) found that AOA determined both picture-naming latency and word retrieval cued by initial bigrams. In all of these studies, words acquired earlier in life were retrieved more rapidly. These findings raise the possibility that the previously reported imagery effects on various memory tasks may actually be the consequence of AOA and that these two variables may have been confounded in earlier research.

With regard to episodic memory tasks, two studies (Gilhooly \& Gilhooly, 1979; Rubin, 1980) examined the relationship between AOA and free recall using correlational analysis. We have reanalyzed a third study (Christian, Bickley, Tarka, \& Clayton, 1978) by adding AOA measures. These three studies show close agreement that there is a modest but significant negative correlation between AOA and recall, with words learned early in life associated with higher recall, but that this correlation evaporates when the high correlations between word imagery and both AOA and recall are taken into account. In the first study, Gilhooly and Gilhooly (1979, Experiment 3) chose 40 words at random from Gilhooly and Hay's (1977) age-of-acquisition norms for five-letter words and tested free recall. As shown in Column 1 of Table 1, the correlation of -.26 between recall and AOA shrinks to -.02 when the effects of rated imagery are par- 
Table 1

Relationship Between Word Imagery, Age of Acquisition (AOA), and Recall in Previous Studies

\begin{tabular}{lccc}
\hline & $\begin{array}{c}\text { Gilhooly and } \\
\text { Gilhooly (1979) } \\
\text { Experiment 3 }\end{array}$ & $\begin{array}{c}\text { Rubin } \\
(1980)\end{array}$ & $\begin{array}{c}\text { Christian } \\
\text { et al. (1978) }\end{array}$ \\
\hline AOA and Recall & Correlations & & \\
Imagery and Recall & -.26 & -.30 & -.38 \\
AOA and Imagery & .42 & .40 & .53 \\
& -.59 & -.59 & -.71 \\
AOA and Recall & Partial Correlations & & \\
Imagery and Recall & -.02 & -.09 & -.01 \\
\hline
\end{tabular}

tialled out. In another study, Rubin (1980) assessed AOA for 125 nouns and tested recall after six different procedures. His overall recall measure (Free Recall Grouped) incorporates data from 214 subjects and has a reliability of .92 by Cronbach's alpha. As the data of Column 2 show, the outcome is the same as for Gilhooly and Gilhooly's data. Finally, Christian et al. (1978) reported the results from an extensive study examining the intercorrelations among four verbal dimensions and free recall for 900 nouns taken from the Paivio, Yuille, and Madigan (1968) imagery norms. Free recall was tested for sublists from 320 subjects. Although age of acquisition was not included among the verbal dimensions reported by Christian et al., they did publish a table giving the recall proportion for each of the 900 words tested. By cross-referencing these recall data with Gilhooly and Logie's (1980) ageof-acquisition norms for 1,944 words, we were able to obtain AOA values for 302 of the 900 words tested by Christian et al. Table 1 shows that the intercorrelations among AOA, word imagery, and recall for these 302 words are comparable to the correlations obtained by Gilhooly and Gilhooly and by Rubin. It should be emphasized that these three studies represent independently obtained estimates of both AOA and recall. In short, the results of three different experiments using different materials agree that there is no evidence of an independent association between the age at which a word is acquired and the word's recallability in a laboratory memory task. Given the amount of evidence from other tasks cited above showing effects of age of acquisition, the lack of an effect on recall is surprising. However, if one accepts Gilhooly and Gilhooly's (1979) argument that those tasks which show an effect of AOA reflect the operations of lexical or semantic memory, as opposed to episodic memory, the contrast is theoretically interesting. Indeed, in his catalog of empirical findings consistent with the distinction between episodic and semantic memory as two different memory systems, Tulving (1983) lists the Gilhooly and Gilhooly (1979) paper on the separate effects of age of acquisition on the two memory systems.

This brings us to the one discrepant finding regarding the relationship between $\mathrm{AOA}$ and episodic memory:
Morris's (1981) rebuttal of Gilhooly and Gilhooly's (1979) methodology and presentation of new evidence that there is indeed a relationship if one looks properly.

There are two parts to Morris's (1981) paper on the effects of age of acquisition on recall. First, a critique is presented of the soundness of Gilhooly and Gilhooly's (1979) stepwise multiple regression in separating out the effects of interrelated variables. The second part of Morris's paper is of considerable importance, because it examines the question of AOA and recall using experimental manipulation and control of the lists, a traditional method of investigating the effects of word variables on memory. Morris constructed two 12-word lists from Gilhooly and Hay's (1977) norms of 205 five-letter words. The two lists differed in AOA but were matched on frequency, imagery, meaningfulness, and, perforce, word length. Not only was there a significant difference by the stringent $\min F^{\prime}$ analysis of Clark (1973), but the difference favored the words that had been acquired later. Given that all of the research cited earlier that shows an effect of AOA has shown that words acquired early have an advantage in lexical/semantic memory tasks, the reversal of direction in Morris's study is puzzling and potentially important.

Fortunately, publication of the Gilhooly and Logie (1980) AOA norms for 1,944 words made it possible to attempt a larger scale replication of Morris's (1981) experiment. Using these materials, we were able to construct two sets of 17-word lists, differing in AOA but matched in frequency, length, and imagery value, and to examine the effects of AOA anew on both free recall and recognition memory. In addition, our recall experiment included an examination of the effects of word imagery with age of acquisition controlled. The high correlation between AOA and imagery, as seen in Table 1, raises the possibility that the well-documented effects of word imagery on recall may be contaminated by AOA, even though substantial partial correlations between imagery and recall remain when AOA is partialled out (see the bottom row of Table 1). Morris attempted such a comparison and obtained results suggestive of an effect of imagery on recall, but the effect was surprisingly small and of marginal statistical significance.

\section{EXPERIMENTS 1a AND 1b Method}

\section{Experiment 1a}

Lists. Two early and two late AOA lists of 17 words each were constructed using the Gilhooly and Logie (1980) AOA norms for 1,944 words. In constructing the lists, the MRC Psycholinguistic Database (M. Coltheart, 1981) was used to make matching on other dimensions less time-consuming. The early and late AOA lists were matched on word imagery (I), word frequency according to the Kučera and Francis (1967) count, and word length in letters. Since research (Gilhooly \& Gilhooly, 1979; Christian et al., 1978) suggests that meaningfulness $(m)$ does not affect recall and recognition when effects of other variables are partialled out, matching on $m$ was not attempted. The means and ranges on AOA, imagery, 
and frequency are shown in Table 2 for the two early and two late age-of-acquisition lists used in Experiment la. It may be noted that the mean AOA values in Morris's study were 2.55 and 5.12 for the early and late acquired words. AOA ratings were obtained by Gilhooly and Logie (1980) using a 7-point scale. In using the scale, subjects rating words for AOA were told that a rating of 1 was equivalent to an estimate that they probably first learned the word at age 0-2 years and a rating of 7 meant that the word was learned after the age of 13 years; intermediate points corresponded to successive 2-year intervals. Matching across age of acquisition on word length was less successful than was matching on imagery and frequency; mean length for the two early AOA lists was 6.06 and 6.12 letters compared with 6.47 letters for each of the two late AOA lists. It may be noted that the lists contain mostly common words, since the high negative correlation between AOA and word frequency makes it very difficult to find early acquired words of low frequency. It may also be noted that the lists are of moderate imagery value.' The 68 words on the AOA lists are provided in Appendix A.

Procedure. The experiment was carried out in a single session in a group setting with each subject tested on each of the four lists. The fours lists of interest were preceded by two practice lists of 17 common words each. Following the two practice lists, the subjects were presented the four experimental lists in the order late, early, early, late. Each word was projected by a Kodak Carousel slide projector with a built-in timer set at a 5-sec rate. Five seconds after the last word, the subjects saw the first of three simple arithmetic problems that they had been told to expect. They were in structed to attempt to solve each problem and record their answers on the answer sheets in front of them. Following the third arithmetic problem, the recall signal was given. The subjects were allowed $90 \mathrm{sec}$ to write down as many words as they could in any order. The same sequence was followed for each of the six lists. From the subject's perspective, there was no difference between the practice and the experimental lists. Forty-four students in an introductory psychology class at the Georgia Institute of Technology served as subjects during regular class time. Data from 2 subjects were discarded because they were not native speakers of English, leaving 42 subjects.

\section{Experiment 1b}

Lists. In order to examine the effects of word imagery on recall with age of acquisition held constant, two lists of high imagery and two lists of low imagery were constructed by choosing words below 3.50 in rated I value for the low imagery lists and words above 5.70 in rated I value for the high imagery lists from the MRC Psycholinguistic Database. There were 20 words on each list. In one

Table 2

Characteristics of Early and Late Acquired Lists Used in Experiment la

\begin{tabular}{lccc}
\hline $\begin{array}{c}\text { Age-of-Acquisition } \\
\text { Lists }\end{array}$ & AOA & Imagery & Frequency* \\
\hline $\begin{array}{l}\text { Early A } \\
\text { Mean }\end{array}$ & 2.66 & 4.37 & 61 \\
Range & $2.32-3.44$ & $3.72-4.98$ & $19-152$ \\
$\begin{array}{l}\text { Early B } \\
\text { Mean }\end{array}$ & 3.00 & & \\
Range & $2.19-3.39$ & $3.41-4.97$ & $16-142$ \\
Late A & & & \\
Mean & 5.16 & 4.21 & 62 \\
Range & $4.58-5.75$ & $3.62-4.73$ & $16-152$ \\
Late B & & & \\
Mean & 5.18 & 4.27 & 53 \\
Range & $4.70-5.86$ & $3.51-5.84$ & $17-149$ \\
\hline
\end{tabular}

*According to Kučra and Francis (1967).
Table 3

Mean Recall of Words Differing in Age of Acquisition and Imagery

\begin{tabular}{llllll}
\hline & \multicolumn{2}{c}{ Set A } & & \multicolumn{2}{c}{ Set B } \\
\cline { 2 - 3 } \cline { 5 - 6 } & $p$ (recall) & SD & & $p$ (recall) & SD \\
\hline Early Acquisition & \multicolumn{2}{c}{ Experiment } & la & & \\
Late Acquisition & .50 & .19 & & .46 & .17 \\
& .46 & .15 & .49 & .14 \\
& Experiment & $1 \mathrm{~b}$ & & \\
Low Imagery & .44 & .14 & .40 & .15 \\
High Imagery & .64 & .18 & .60 & .18 \\
\hline
\end{tabular}

pair of lists, Set A, the mean AOA values for the low and high imagery lists were 3.12 and 3.37; the medians were 3.24 and 3.52. For these two lists, the word frequencies were high; the mean Kucera-Francis frequencies were 110 and 152 (medians of 96 and 124) for the high imagery and low imagery lists, respectively. For the other pair of lists, Set B, the lists again varied in rated I and were matched on age of acquisition and frequency. However, for these lists, the words were both later in AOA and less frequent. These differences were necessitated by the high inverse correlations between AOA and both imagery and frequency. For the high imagery list, the mean AOA was 4.62 (median $=4.58$ ) and the mean frequency was 36 (median $=12$ ); for the low imagery list, the mean $\mathrm{AOA}$ was 4.78 (median $=4.82$ ) and the mean frequency was 30 (median $=20$ ). For each pair of lists, one can examine recall as a function of imagery value with $\mathrm{AOA}$ and frequency controlled. The 80 words on the imagery lists are listed in Appendix B.

Procedure. The procedure was essentially the same as in Experiment 1a, except that two groups of subjects were tested. Nine subjects were presented the four experimental lists, following the two practice lists, in the sequence High I, Low I, Low I, High I, whereas the other 11 subjects were presented the lists in the sequence Low I, High I, High I, Low I. Arithmetic problems preceded free recall for each list. The 20 subjects were Emory University students in introductory psychology courses who participated for course credit.

\section{Experiment 1a}

\section{Results}

Mean recall by subjects for each of the four lists is shown in Table 3. It should be noted again that the two sets of lists are for purposes of replication. Table 3 shows that whatever difference in recall is associated with age of acquisition of the word slightly favors the words acquired earlier. Statistical analysis, however, indicates that the differences are not reliable. In reporting statistical analyses, we will report the outcomes of separate analyses over subjects and words. For the analysis over subjects, neither age of acquisition $[F(1,41)=2.15]$, nor lists $[F(1,41)=1.39]$, nor their interaction $(F<1)$ was significant. For the analysis over words, all $F \mathrm{~s}<1.0$. Thus, Morris's finding of greater recall for words acquired late was not replicated with either set of lists. Indeed, the observed differences, although not significant, are in the opposite direction from Morris's results.

\section{Experiment 1b}

The recall results for word imagery are shown in Table 3 . For each of the two sets, recall is substantially higher for the high imagery words. The difference is sig- 
nificant for both sets of lists, whether subjects or words are the unit of analysis [for subjects, $F(1,38)=15.32$, $p<.01$, for Set $A$ and $F(1,38)=16.24, p<.01$, for Set B; for words, $F(1,38)=12.18, p<.01$, for Set A and $F(1,38)=16.16, p<.01$, for Set B]. These data show that the robust effects of word imagery on recall remain when the age at which the words are acquired is controlled for. An additional analysis which included list order as a factor indicated that it had no significant effect on performance, and that list order did not interact with imagery.

\section{EXPERIMENT 2}

The next experiment inquired into the relationship between recognition memory and word age of acquisition. There are two studies pertinent to this issue. Gilhooly and Gilhooly (1979, Experiment 4) presented subjects with 100 five-letter words chosen from the Gilhooly and Hay (1977) norms, followed by a two-alternative forced-choice test of recognition memory. They found a significant correlation of .41 between recognition scores and AOA, but also found a significant correlation of -.45 between word frequency and recognition. A multiple regression analysis, however, attributed $21 \%$ of the variance in recognition memory to word frequency and only $2 \%$ to word age of acquisition. Morris (1981) criticized Gilhooly and Gilhooly in this regard, as follows:

By beginning the stepwise multiple regression with frequency and following with age Gilhooly and Gilhooly concluded that frequency accounts for $21 \%$ of the criterion variance and age only $2 \%$. If they had begun with age of acquisition age would have apparently accounted for $17 \%$ of the variance and frequency only $5 \%$. Clearly very different interpretations might be drawn from these two analyses.

(p. 278)

As Morris pointed out, the probable unreliability of the criterion measure, recognition memory, makes the .04 difference which determined the order of entry into the analysis less than satisfying. Is there a relationship between word age of acquisition and recognition memory, an episodic memory task, as the positive correlation of .41 found by Gilhooly and Gilhooly suggests? If it is to be taken seriously, it is in the same direction as the effect reported by Morris for recall, with later words better remembered.

A more conservative examination of Gilhooly and Gilhooly's (1979) correlation matrix suggests that their positive correlation between recognition and age of acquisition is largely due to the high negative correlation of -.68 between AOA and word frequency and the high negative correlation of -.45 between recognition and frequency. When a partial correlation between recognition and AOA is calculated with word frequency and imagery accounted for, the resulting correlation is .15 , which is not significant.
The other piece of evidence relevant to the relationship between recognition memory and word age of acquisition is the correlation of -.23 found by Rubin (1980). Although significant, the correlation is in the opposite direction to the positive correlation found by Gilhooly and Gilhooly. However, when a second-order partial correlation between recognition memory and AOA is calculated for Rubin's data with word imagery and frequency held constant, the resulting partial correlation is -.02 . On the basis of the Gilhooly and Gilhooly (1979) and Rubin (1980) studies, then, any effect of word age of acquisition on recognition memory seems attributable to the intercorrelations between $A O A$ and imagery value and frequency. The next experiment examined the relationship between recognition memory and AOA, with imagery and frequency held constant. As in Experiments 1a and 1b, the effects of word imagery were assessed as well. Since some word properties, such as frequency, have a greater effect on recognition memory when mixed (rather than pure) lists are used (Gregg, 1976), a mixed list design was used. This also reduced the possibility that ceiling effects would be obtained, since the lists could be longer.

\section{Method}

Lists

From the words used in Experiments la and $1 \mathrm{~b}$, two lists of 72 words each were made up. Each list contained completely different words: 17 early AOA words, 17 late AOA words, 19 high imagery words, and 19 low imagery words. The words were assigned to the two lists randomly, so the composition of the lists in this study was different from that of Experiment 1, although the words were the same. A few words were omitted because of overlap between the AOA and imagery words. For the two-alternative forcedchoice recognition test, each word was paired with a word of the same class from the other list. The spelling of a few words was changed to conform with British usage (e.g., labour and favourite). The study list was presented on slides in white lowercase print on a blue background. The recognition test showed pairs of words beside each other in a typed questionnaire, and two versions of the test, in which the items were in different random orders, were constructed.

\section{Procedure}

Each word was presented for $3 \mathrm{sec}$ by a Kodak Carousel projector controlled by an external timer. The interslide interval was approximately $1.4 \mathrm{sec}$. Subjects were tested in several groups. The recognition test was administered $1 \mathrm{~h}$ later. Subjects attended a lecture during the retention interval. The subjects were City of London Polytechnic Modular Degree students attending lectures in psychology, geography, biology, and sociology. Fifty-five subjects were tested on List 1 and 51 on List 2. The data of 2 additional subjects were discarded due to omissions on the test, and the data from another 4 randomly chosen subjects who saw List 1 were discarded in order to have groups of equal size (51) on the two lists.

\section{Results}

Mean proportion correct recognition by subjects for the words varying in AOA on the lists is presented in the top half of Table 4. An analysis of variance in which lists (List 1/List 2) was a between-subjects factor and age of acquisition (early/late) was a within-subjects factor was carried out. This indicated that although there were no 
Table 4

Recognition Performance for Words Differing in Age of Acquisition and Imagery

\begin{tabular}{lccccc}
\hline & \multicolumn{2}{c}{ List 1 } & & \multicolumn{2}{c}{ List 2 } \\
\cline { 2 - 3 } \cline { 5 - 6 } & $\begin{array}{c}\text { Mean Proportion } \\
\text { Correct }\end{array}$ & SD & $\begin{array}{c}\text { Mean Proportion } \\
\text { Correct }\end{array}$ & SD \\
\hline Early Acquisition & .78 & .14 & .72 & .15 \\
Late Acquisition & .77 & .16 & .78 & .14 \\
High Imagery & .87 & .10 & .84 & .10 \\
Low Imagery & .80 & .13 & .71 & .13 \\
\hline
\end{tabular}

significant main effects of Lists $(F<1)$ or of age of acquisition $[F(1,100)=3.40]$, there was a significant interaction between these two variables $[F(1,100)=6.22$, $p<.05]$. Simple main effects tests indicated that for List 2, late acquired words were better recognized than early acquired words $[F(1,100)=9.40, p<.01]$. For List 1, performance did not differ on these two types of words $(F<1)$.

Analyses over words indicated no significant differences for either lists $(F<1)$ or age of acquisition $[F(1,64)=$ 2.09] and no significant interaction between these two variables $[F(1,64)=2.86]$. Thus, it would appear that when imagery is controlled, age of acquisition does not reliably affect recognition memory. The difference between early and late acquired words for List 2 did not emerge in the analysis of words.

A similar analysis was performed on words varying in imagery for the two lists. Performance on these words is shown in the bottom of Table 4. Analysis over subjects showed that List 1 was significantly easier than List 2 $[F(1,100)=10.07, p<.01]$. High imagery words were easier to remember than were low imagery words $[F(1,100)=60.95, p<.001]$, and there was a significant interaction between lists and imagery $[F(1,100)=$ $5.80, p<.05]$. Simple main effects tests indicated that although there was no significant difference in recognition for high imagery words on the two lists $[F(1,200)$ $=2.07 \mathrm{l}$, low imagery words from List 1 were significantly easier to recognize than were low imagery words from List $2[F(1,200)=15.73, p<.01]$.

Analyses over words for imagery confirmed the analyses over subjects for the main effects. List 1 was significantly easier than List $2[F(1,72)=9.51, p<.01]$, and high imagery words were much easier to recognize than low imagery words $[F(1,72)=21.63, p<.001]$. The interaction between lists and imagery, however, was not significant $[F(1,72)=2.30]$. These results indicate that when age of acquisition is controlled, word imagery continues to be a potent variable determining recognition memory.

\section{DISCUSSION}

The major conclusion of the literature surveyed, and in some cases reanalyzed, is that there is no reliable effect of the age at which words are acquired on episodic memory tasks when word imagery and frequency are held constant. In recall, there was no effect of AOA on two lists. For recognition memory, words acquired late were better recognized than were words acquired early for one set of lists, but the effect was not reliable when assessed by a stimulus analysis. Thus, our results agree with the earlier studies of Christian et al. (1978), Gilhooly and Gilhooly (1979), and Rubin (1980). They are, however, inconsistent with the findings of Morris (1981). Therefore, we examined the words in Morris's experiment more closely. Inspection of Morris's late acquired words suggested that this list had more words high in emotional connotation (e.g., lover, vodka, ovary, youth) than were present in the list of early acquired words. Since Rubin (1980) found a significant positive correlation between ratings of word emotionality and recall, the possibility of a difference in emotionality in Morris's lists was explored. Forty-one undergraduates at the City of London Polytechnic were asked to provide emotionality ratings for each of the 24 words used by Morris (1981) on a 7-point scale. The mean emotionality ratings obtained for the early and late AOA lists were 2.42 and 3.02 , respectively. The finding of greater emotionality ratings for the late AOA words was significant $[t(40)=6.70, p<.001]$. The difference between the lists can be seen by the following examples. The early AOA list contained only one word with a high mean emotionality rating, filth (4.15), and two other words with ratings above 3.0 : prize (3.05) and fairy (3.17). In contrast, the late AOA list included lover (5.44) and seven other words with ratings above 3.0. However, an analysis over words was not significant $[t(22)=1.61]$, perhaps due to the small number of words per list (12).

Theoretically, it appears reasonable to argue that those tasks which are sensitive to the chronological age at which words enter the lexicon are tasks which are commonly viewed as measuring semantic memory. Episodic memory tasks, at least free recall and recognition memory, appear to be insensitive to age of acquisition when appropriate variables have been controlled for, either statistically, as in the work of Christian et al. (1978), Gilhooly and Gilhooly (1979), and Rubin (1980), or experimentally, as in the present work.

A recent study suggests, however, that not all semantic memory tasks are sensitive to age of acquisition: Gilhooly and Logie (1982) found that decision speed in the lexical decision task was not affected by AOA. They suggest that only tasks involving word production (the literature reviewed in the introduction) may be sensitive to AOA. The lexical decision task involves only a yes-no decision as to whether the target item is an English word and, therefore, overt production is not required. If one takes this position, however, the question remains as to why lexical output processes are sensitive to AOA in picture naming (Lachman, 1973) and word completion from fragment cues (Gilhooly \& Gilhooly, 1979) but not in free recall. Certainly, free recall involves lexical output; indeed, an earlier generation referred to it as the method of reproduction. The obvious answer, that lexical output 
processes are sensitive to AOA only in semantic memory tasks such as naming and word completion, is less than satisfactory, on the grounds that it invokes both a process explanation and a systems explanation to deal with a set of data that, while not simple, do not seem commensurate with such weighty assumptions. It would seem preferable at this stage to regard the literature concerning AOA and memory as phenomena in search of a parsimonious explanation rather than to assume prematurely that a satisfactory explanation is available.

Finally, the results of both experiments leave little doubt that both recall and recognition are strongly influenced by word imagery when AOA is controlled. Although it is plausible that word imagery effects might be attributed to the high inverse correlation between word imagery and AOA-after all, we do not speak in abstract words to 2year-old children-in fact, the word imagery effect in memory tasks is not an artifact of differences in the age at which the words were first learned. Word imagery remains a robust determinant of memory.

\section{REFERENCES}

Carroll, J. B., \& White, M. N. (1973). Word frequency and age of acquisition as determiners of picture-naming latency. Quarterly Journal of Experimental Psychology, 25, 85-95.

Christian, J., Bickley, W., Tarka, M., \& Clayton, K. (1978). Measures of free recall of 900 English nouns: Correlations with imagery, concreteness, meaningfulness, and frequency. Memory \& Cognition, 6, 379-390.

Clark, H. H. (1973). The language-as-fixed-effect fallacy: A critique of language statistics in psychological research. Journal of Verbal Learning \& Verbal Behavior, 12, 335-359.

ColthearT, M. (1981). The MRC psycholinguistic database. Quarterly Journal of Experimental Psychology, 33A, 497-505.

Epstein, W., Rock, I., \& ZuCKerman, C. B. (1960). Meaning and familiarity in associative learning. Psychological Monographs, 74(4, Whole No. 491).

Gilhooly, K. J., \& Gilhooly, M. L. (1979). Age-of-acquisition ef fects in lexical and episodic memory tasks. Memory \& Cognition, 7 214-223.

Gilhooly, K. J., \& Gilhooly, M. L. (1980). The validity of age-ofacquisition ratings. British Journal of Psychology, 72, 105-110.

Gilhooly, K. J., \& HAY, D. (1977). Imagery, concreteness, age-ofacquisition, familiarity, and meaningfulness values for 205 five-letter words having single-solution anagrams. Behavior Research Methods \& Instrumentation, 9, 12-17.

GILHOOLY, K. J., \& LoGIE, R. H. (1980). Age-of-acquisition, imagery, concreteness, familiarity, and ambiguity measures for 1,944 words. Behavior Research Methods \& Instrumentation, 12, 395-427.

Gilhooly, K. J., \& Logie, R. H. (1982). Word age-of-acquisition and lexical decision making. Acta Psychologica, 50, 21-34

Gorman, A. M. (1961). Recognition memory for nouns as a function of abstractness and frequency. Journal of Experimental Psychology, 61, 23-29.

GREGG, V. (1976). Word frequency, recognition and recall. In J. Brown (Ed.), Recall and recognition (pp. 183-216). London: Wiley.

KuCERA, N., \& FrancIS, W. N. (1967). Computational analysis of present-day American English. Providence, RI: Brown University Press.

LACHMAN, R. (1973). Uncertainty effects on time to access the internal lexicon. Journal of Experimental Psychology, 99, 199-208.
Lachman, R., Shaffer, J. P., \& Hennrikus, D. (1974). Language and cognition: Effects of stimulus codability, name-word frequency, and age-of-acquisition on lexical reaction time. Journal of Verbal Learning \& Verbal Behavior, 13, 613-625.

Loftus, E. F., \& Suppes, P. (1972). Structural variables that determine the speed of retrieving words from long-term memory. Journal of Verbal Learning \& Verbal Behavior, 11, 770-777.

Morris, P. E. (1981). Age of acquisition, imagery, recall, and the limitations of multiple-regression analysis. Memory \& Cognition, 9, 277-282.

Paivio, A. (1963). Learning of adjective-noun paired associates as a function of adjective-noun word order and noun abstractness. Canadian Journal of Psychology, 17, 370-379.

Paivio, A., Yuille, J. C., \& Madigan, S. A. (1968). Concreteness, imagery, and meaningfulness values for 925 nouns. Journal of Experimental Psychology Monograph Supplement, 76, 1-25.

Paivio, A., Yuille, J. C., \& Rogers, T. B. (1969). Noun imagery and meaningfulness in free and serial recall. Journal of Experimental Psychology, 79, 509-514.

RuBin, D. (1980). 51 Properties of 125 words: A unit analysis of verbal behavior. Journal of Verbal Learning \& Verbal Behavior, 19 , 736-755.

STоKE, S. M. (1929). Memory for onomatopes. Journal of Genetic Psychology, 36, 594-596.

Tulving, E. (1983). Elements of episodic memory. Oxford: Oxford University Press.

Tulving, E., McNulty, J. A., \& OzIER, M. (1965). Vividness of words and learning to learn in free recall learning. Canadian Journal of Psychology, 19, 242-252

YARMEY, A. D., \& PaIvio, A. (1965). Further evidence on the effects of word abstractness and meaningfulness in paired-associate learning. Psychonomic Science, 2, 307-308.

\section{NOTE}

1. In response to a reviewer's request, correlations were obtained between AOA, word imagery, and frequency for the 68 words used in Experiment 1a. These correlations were small: AOA and I, $r=-.24$; $\mathrm{AOA}$ and frequency, $r=-.01$.

\section{APPENDIX A} Age-of-Acquisition Lists $A$ and $B$

\begin{tabular}{llll}
\hline \multicolumn{1}{c}{ Early A } & \multicolumn{1}{c}{ Late A } & \multicolumn{1}{c}{ Early B } & \multicolumn{1}{c}{ Late B } \\
\hline answer (1) & congress (1) & hurt (2) & agency (2) \\
bother (2) & salary (2) & block (1) & amateur (1) \\
cousin (2) & buffer (1) & hide (1) & chlorine (2) \\
distance (2) & freight (2) & minute (1) & clerk (1) \\
favorite (2) & grant (2) & fifteen (1) & conflict (1) \\
hate (1) & liberty (2) & luck (2) & debate (1) \\
heaven (2) & dignity (1) & height (1) & denial (2) \\
lesson (1) & dispute (1) & finish (2) & device (2) \\
primary (2) & vice & goodness (1) & graph (2) \\
prize (1) & career (1) & addition (2) & illusion (2) \\
sold (2) & security (1) & pattern (1) & income (2) \\
spell (2) & reaction (1) & learning (1) & justice (2) \\
stranger (2) & pioneer (2) & blame (1) & labor (1) \\
surprise (1) & circuit (2) & breath (2) & lumber (1) \\
throw (2) & index (2) & opening (1) & majority (1) \\
touch (2) & volume (1) & object (1) & review (2) \\
trouble (2) & permit (2) & wonder (1) & venture (1) \\
\hline
\end{tabular}

Note-For each word, (I) and (2) indicate the recognition list in which it occurred. 
APPENDIX B

Word Imagery Lists A and B

\begin{tabular}{llll}
\hline \multicolumn{1}{c}{ High A } & \multicolumn{1}{c}{ Low A } & \multicolumn{1}{c}{ High B } & \multicolumn{1}{c}{ Low B } \\
\hline brother (1) & try (1) & wine (1) & pause (2) \\
money (2) & wrong (2) & planet (2) & hint (1) \\
window (1) & guess (1) & furnace (1) & ease (2) \\
hospital (2) & anybody (2) & athlete (2) & respect (1) \\
woman (1) & addition & menu (2) & belief (1) \\
body (2) & part & highway (1) & proof (2) \\
island (1) & extra (2) & disc (2) & extreme (2) \\
oil (2) & nonsense (1) & olive (1) & incident (1) \\
building (2) & thought (1) & president (2) & scheme (2) \\
uniform (1) & moment (2) & examination (1) & indication (1) \\
radio (2) & usual (2) & dormitory (1) & inquiry (1)
\end{tabular}

Appendix B (Continued)

\begin{tabular}{llll}
\hline \multicolumn{1}{c}{ High A } & \multicolumn{1}{c}{ Low A } & \multicolumn{1}{c}{ High B } & \multicolumn{1}{c}{ Low B } \\
\hline market (1) & impossible (2) & crucifix (2) & transfer (2) \\
valley (2) & excuse (1) & automobile (1) & origin (2) \\
grave (1) & main (1) & bosom & judgement (1) \\
minister (1) & spare (1) & embrace (2) & pretence (2) \\
liquid (2) & worth (2) & cologne (1) & outset (1) \\
clay (1) & normal (2) & fountain (1) & deceit (1) \\
cellar (2) & position (1) & saxophone (2) & namesake (2) \\
wound (2) & difference (1) & inferno (2) & forfeit (2) \\
moonlight (1) & reason (2) & physician (1) & alias (1) \\
\hline
\end{tabular}

Note-For each word, (1) and (2) indicate the recognition list in which it occurred. 